\title{
Tuberculosis and noncommunicable diseases: neglected links and missed opportunities
}

\author{
J. Creswell*, M. Raviglione*, S. Ottmani*, G.B. Migliori”, M. Uplekar*, L. Blanc*, \\ G. Sotgiu" and K. Lönnroth*
}

ABSTRACT: Globally, the incidence of tuberculosis (TB) is declining very slowly, and the noncommunicable disease (NCD) burden for many countries is steadily increasing. Several NCDs, such as diabetes mellitus, alcohol use disorders and smoking-related conditions, are responsible for a significant proportion of TB cases globally, and in the European region, represent a larger attributable fraction for TB disease than HIV. Concrete steps are needed to address NCDs and their risk factors. We reviewed published studies involving TB and NCDs, and present a review and discussion of how they are linked, the implications for case detection and management, and how prevention efforts may be strengthened by integration of services. These NCDs put patients at increased risk for developing TB and at risk for poor treatment outcomes. However, they also present an opportunity to provide better care through increased casedetection activities, improved clinical management and better access to care for both TB and NCDs. Hastening the global decline in TB incidence may be assisted by strengthening these types of activities.

KEYWORDS: Alcohol, diabetes, malnutrition, noncommunicable disease, smoking, tuberculosis

W hile infectious disease has dominated the disease burden in the developing world for much of the last century, the incidence of many noncommunicable diseases (NCDs), such as cardiovascular diseases, diabetes mellitus (DM), those related to smoking and alcohol abuse, chronic obstructive pulmonary disease (COPD), and mental illness, is growing in low- and middle-income countries, as well as in certain populations in high-income countries. This epidemiological shift adds to the existing infectious disease load, creating a double burden of communicable diseases and NCDs in these populations [1-12]. NCDs have often been depicted as diseases of development and it is a common notion that they mainly affect the nonpoor. However, most NCDs, like most infectious diseases, are more common in the lower socioeconomic groups. This is certainly true in highincome countries, but also to a growing extent also in middle- and low-income countries [13]. Therefore, the double burden of communicable diseases and NCDs is most pronounced among the poor, and this is further underscored by the causal links between them. There is a growing body of evidence describing the links between tuberculosis (TB) and a number of NCDs and their risk factors, such as DM, smoking- and alcohol-related conditions, COPD, mental illness and malnutrition [14-17].

Previous articles in this series: No. 1: Erkens CGM, Kamphorst M, Abubakar I, et al. Tuberculosis contact investigation in low prevalence countries: a European consensus. Eur Respir J 2010; 36: 925-949. No. 2: Solovic I, Sester M, Gomez-Reino JJ, et al. The risk of tuberculosis related to tumour necrosis factor antagonist therapies: a TBNET consensus statement. Eur Respir J 2010; 36: 1185-1206. No. 3: Schutz C, Meintjes G, Almajid F, et al. Clinical management of tuberculosis and HIV-1 co-infection. Eur Respir J 2010; 36: 1460-1481. No. 4: Yew WW, Lange C, Leung CC. Treatment of tuberculosis: update 2010. Eur Respir J 2011; 37: 441-462. No. 5: Leung CC, Rieder HL, Lange C, et al. Treatment of latent infection with Mycobacterium tuberculosis: update 2010. Eur Respir J 2011; 37: 690-711. No. 6: Veen J, Migliori GB, Raviglione MC, et al. Harmonisation of TB control in the WHO European region: the history of the Wolfheze Workshops. Eur Respir J 2011; 37: 950-959.

AFFILIATIONS

*Stop TB Dept, World Health Organization, Geneva, Switzerland. *WHO Collaborating Centre for TB and Lung Disease, Fondazione $\mathrm{S}$. Maugeri, Care and Research Institute, Tradate, and

"Hygiene and Preventive Medicine Institute, University of Sassari, Sassari, Italy.

CORRESPONDENCE

J. Creswell

Stop TB Dept

World Health Organization

20 Avenue Appia

Geneva 1211

Switzerland

E-mail: creswellj@who.int

Received:

May 312010

Accepted after revision:

Sept 042010

First published online:

Oct 142010 
TB has long been a disease of the poor. Crowded living conditions and compromised immune systems due to causes such as under-nutrition have contributed to a disease that caused one in every seven deaths in late 19th-century Europe, and which continues to cause immense human suffering across the world today. Although many lives have been saved by widely available and inexpensive TB treatment over the past decades, due to the expansion of DOTS as a global management strategy [18], TB continues to be a leading cause of burden and death among infectious diseases worldwide [19]. Furthermore, the growing problem of multidrug-resistant (MDR) and extensively drug-resistant TB has been well documented, especially in the European region, and poses a great challenge to treatment and care [20-22]. Globally, TB incidence is declining, but at a slow pace [23]. Additional efforts are needed to speed up the decline. Improved diagnosis and treatment of all forms of $\mathrm{TB}$ will be required, backed by poverty alleviation and general socioeconomic development, for long-term TB control and elimination. However, there is also a need to address a set of major TB risk factors and comorbidities [18].

HIV infection has driven the TB epidemic in sub-Saharan Africa, and the links between TB and HIV have been well documented [24]. There has been an intense focus on improved TB/HIV collaboration in recent years, with an aim to: 1) improve early TB diagnosis and treatment among people with HIV infection and, vice versa, improve clinical outcomes for both diseases; 2) use isoniazid as TB preventive therapy as well as cotrimoxazole preventive treatment for opportunistic infections in people with HIV infection; and 3) promote contribution by national TB programmes to HIV prevention and thus, indirectly, TB prevention [25]. Lessons and models of TB/HIV collaboration [26] may be applied to noncommunicable comorbidities. The dual epidemics of TB and HIV have led to the use of the phrase "two diseases, one patient", but with an increasing prevalence and focus on NCD, clinicians treating TB need to acknowledge that they may deal with multiple diseases in a single patient.

Several NCDs, such as DM, alcohol use disorders and smoking-related conditions, are responsible for a significant proportion of TB cases [18]. These risk factors are particularly important attributable factors in the European region, where their prevalence is much higher than, for example, the prevalence of HIV and under-nutrition [27-29]. With the ongoing epidemiological transition, the disease and risk factor patterns in low- and middle-income countries may resemble those of Europe in coming decades. COPD is now the fourth leading cause of death globally and is expected to be the third by 2030 [30]. DM prevalence is expected to more than double by 2030, and seven out of the 10 expected high-burden countries for DM in 2030 are high-burden TB countries today [31]. Alcohol consumption seems to be increasing in most developing countries, following a general rule that as people have better access and purchasing power, consumption increases, while those with low socioeconomic status have the highest risk of harmful use [32-34]. In this article, the term $\mathrm{NCD}$ is used to refer to a group of noncommunicable diseases (e.g. DM, alcohol dependency, COPD, malnutrition, mental illness and silicosis) and their related risk factors (e.g. smoking, poor diet and heavy drinking).
The rise of NCDs is important for TB control for a variety of reasons. First, many NCDs are risk factors for TB, especially for progression from infection to disease due to negative impact on host defense mechanisms against Mycobacterium tuberculosis [17, 35-39]. Secondly, NCDs may complicate treatment and management of $\mathrm{TB}$, due to clinical challenges (e.g. among people with $\mathrm{DM}$ ) as well as behavioural challenges (e.g. among people with alcohol use disorders) [40, 41]. Thirdly, TB can trigger or aggravate NCDs. For instance, TB, like other infections, can worsen glucose control and trigger DM [40], and a history of $\mathrm{TB}$, although not a classical risk factor for COPD, is one of the leading causes of lung sequelae and bronchiectasis, and has been identified as an independent risk factor for COPD in a recent review [42]. In addition, TB, and especially MDR-TB, may aggravate the social and financial stress contributing to substance abuse and mental illness [43].

However, the link between TB and NCDs also creates opportunities for improved diagnosis and management of both. Presence of a NCD may indicate the need to actively screen for $\mathrm{TB}$, especially in high-burden countries, which can help improve early and increase TB case detection [44]. Similarly, diagnosis of TB should alert clinicians to actively screen for common noncommunicable comorbidities, which may otherwise go undiagnosed, especially in low- and middleincome countries where services for NCDs are vastly underdeveloped. Finally, preventive therapy for TB may be warranted in individuals with some of these comorbidities.

While there have been a number of reviews of relationships between certain NCDs and TB [16, 17, 29, 45, 46], a discussion of the implications that the expected growth in NCD prevalence on TB will have and what can be done to address the situation is needed.

In this article, we discuss the overall knowledge base concerning $\mathrm{TB}$ and the related NCDs, and then examine the implications for both increased case detection and improved clinical management of TB and NCDs. Finally, we suggest how prevention efforts might be strengthened and the implications of the growing NCD burden for TB control programmes and how to work with NCD programmes to improve service and care.

\section{METHODS}

We searched PubMed, the Cochrane library and the e-mail list "TB-Related News and Journal Items Weekly Update" (prepared by the Centers for Disease Control and Prevention, Atlanta, GA, USA), and relied on previously identified key publications. The available literature was searched from inception until May 2010 inclusive. We purposively selected the publications that were judged most relevant for the review, with a preference for highquality systematic reviews. We favoured publications in the past 5 yrs, but did not exclude highly regarded older publications. The search was conducted using multiple combinations of the following key words: "tuberculosis", "alcohol", "silicosis", "COPD", "smoking", "diabetes", "malnutrition", "nutrition", "mental health", "prevalence" and "incidence".

\section{LINKS BETWEEN NCD AND TB Diabetes mellitus}

A systematic review of 13 observational studies reported a relative risk (RR) of TB in patients with DM of 3.1 in cohort 
studies and ORs that ranged 1.16-7.83 in case-control studies [14]. These results were similar to those reported in a previous systematic review [47] and further supported by a recent narrative review emphasising the link between TB and DM [48]. The potential public health importance of this link has been underscored by an epidemiological model suggesting that DM might account for nearly $15 \%$ of pulmonary tuberculosis in India [49]. An analysis of the population attributable fractions of different risk factors for TB in different WHO regions suggests that DM is the second most important factor in the central Europe region and among established market economies (table 1). Other conditions, such as chronic renal disease, are long-term consequences of DM and linked to $\mathrm{TB}$, although it is unclear how much risk can be attributed directly to the conditions. Furthermore, given that the prevalence of $\mathrm{DM}$ is expected to increase rapidly in the coming decades, it could become an even more important factor in all regions. An expert meeting on TB and DM in 2009 considered the findings in these reviews as well as findings in a new, and presently unpublished, extended systematic review. The meeting concluded that a causal relationship between DM and TB is likely, but further research is needed to verify earlier results and to better document the strength of the association and the possible causal mechanisms. The meeting also concluded that some studies have showed increased TB risk with poorer glucose control, and that there is a lack of evidence for increased risk of TB infection among people with DM. There is some evidence that DM leads to delayed culture conversion [50,51] and that the risk of death during TB treatment is increased [52, 53], as was the risk of relapse [54, 55]. The evidence base on the link between DM and acquired drug resistance is mixed and inconclusive. Finally, it has been argued that prolonging the standard TB treatment regimen for people with DM may improve outcomes, but presently, little data exist to support the claim [40]. There are no quality data on the effectiveness and feasibility of early case detection and chemoprophylaxis of TB among diabetics.

\section{Alcohol}

A systematic review of observational studies on the link between alcohol consumption and risk of TB concluded that people who consume, on average, $>40 \mathrm{~g}$ alcohol a day (heavy drinkers) and/or have an alcohol-use disorder have three times the risk of developing $\mathrm{TB}$, while low-to-medium alcohol consumption does not seem to increase the risk of disease [29]. A subsequent narrative review of epidemiological studies, clinical research and animal studies concluded that this association seems to be causal [41]. While the relative importance of adverse effects on the immune system of alcohol versus increased risk of transmission due to the pattern of social interactions among heavy drinkers is not clear, both factors are likely important. Heavy drinkers may be more exposed to $M$. tuberculosis in bars, prisons, shelters or other congregate settings. Alcohol use-related health disorders are associated with several clinical conditions that may impair the immune system. In addition, alcohol has a direct toxic effect on the immune system. Animal studies suggest that chronic and acute alcohol consumption impairs cell-mediated immunity and macrophage functions (which are essential for the host response to $M$. tuberculosis infection) [36, 56]. Furthermore, heavy alcohol use may be a secondary cause of micro- and macronutrient deficiency, which can also impair immunity [57]. Excessive alcohol use is also associated with poor TB treatment adherence, and a number of studies have found higher relapse rate among heavy drinkers and those with alcohol use-related health disorders [41]. Though it would be plausible that this would also increase the risk of MDR-TB, there is presently no strong evidence base supporting this hypothesis. Alcohol abuse is a common TB risk factor in Eastern Europe and Latin America (table 1). There is very little

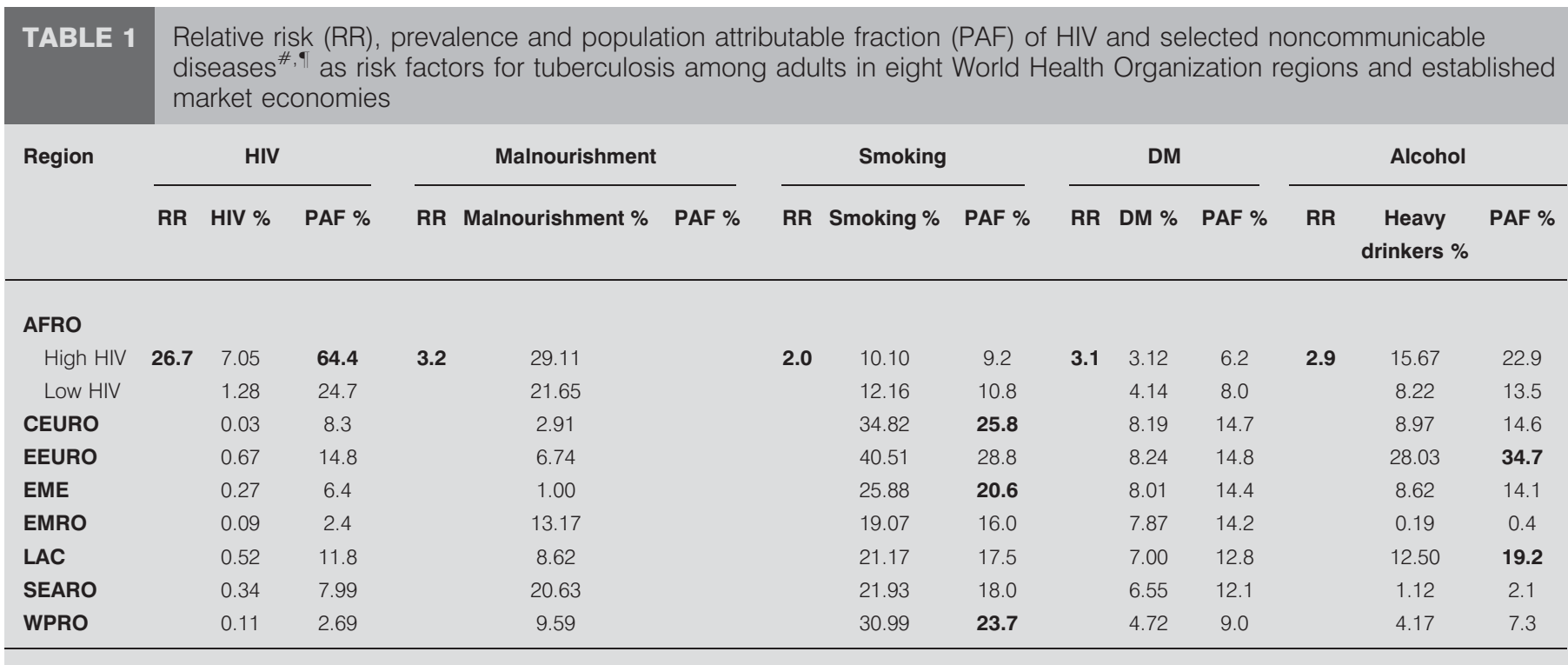

DM: diabetes mellitus; AFRO: African region; CEURO: Central European region; EEURO: Eastern European region; EME: established market economies; EMRO: eastern Mediterranean region; LAC: Latin American and Caribbean region; SEARO: South-East Asian region; WPRO: Western Pacific region. ${ }^{*}$ : DM is the main risk factor for chronic renal disease and data on chronic renal disease without DM were not available; " ${ }^{\natural}$ data on mental illnesses were not available for this table. 
published data on the effectiveness, cost-effectiveness and feasibility of TB screening and preventive chemotherapy among people with alcohol-use disorders.

\section{Smoking and COPD}

Mathematical modelling has shown the potential importance of smoking and suggested that a large part of the tuberculosis burden in many regions of the world can be attributed to smoking (table 1). Two recent systematic reviews on smoking and TB concluded that smokers have a two to three times elevated risk of $\mathrm{TB}$, and that there is a dose-response relationship for both quantity of cigarettes and duration of smoking, after adjustment for alcohol intake and socioeconomic status $[16,58]$. There is also evidence linking passive smoking to higher TB risk, especially in children [16]. The biological explanation of the casual relationship between smoking, and tuberculosis infection and disease has been increasingly well documented. The tracheobronchial mucosal surface is a first level of host defense that prevents $M$. tuberculosis from reaching the alveoli. Tobacco and other environmental pollutants may impair this defense mechanism [59]. Smoke also impairs the function of pulmonary alveolar macrophages [38]. Nicotine is hypothesised to act directly on nicotinic acetylcholine receptors on macrophages to decrease intracellular tumour necrosis factor- $\alpha$ production and, thus, impair intracellular killing of $M$. tuberculosis [39]. It is still unclear if COPD is a risk factor for TB, independently from smoking [60]. However, TB history seems to be an independent risk factor for COPD [6, 61-64]. COPD is, therefore, a marker for both smoking and previous TB (which also is a risk factor for future TB disease), and thus a predictor of risk.

Smoking also affects the chance of cure from TB. Severity of TB at the time of diagnosis and risk of relapse have been linked to smoking. In addition, a few studies have found that smokers have a higher risk of death from TB and other poor treatment outcomes than nonsmokers [16]. A number of studies from the UK and USA also found an independent association between COPD comorbidity and death in TB patients, although others found no effect. Problems controlling for the effects of smoking may be partially to blame for the lack of clear evidence [45].

\section{Malnutrition}

Malnutrition is a cause of tuberculosis disease and wasting is a consequence of $\mathrm{TB}$, which explains why a large proportion of $\mathrm{TB}$ patients are undernourished at the time of diagnosis. The ecological evidence linking declines in TB to better nutrition has long been clear [65-67]. It has been difficult to verify this link through analytical epidemiology, mainly because the temporal relationship is difficult to establish with cross-sectional data obtained at the time of TB diagnosis. However, a recent systematic review of prospective cohort studies found a consistent log-linear inverse relationship between baseline body mass index (BMI) and subsequent TB incidence [68]. There was a reduction of incidence of almost $14 \%$ for each unit of BMI increase, which was consistent between BMI 18.5 and $30 \mathrm{~kg} \cdot \mathrm{m}^{-2}$. It is interesting to note that obesity may be protective against $\mathrm{TB}$, with one large cohort study showing significantly lower risk of $\mathrm{TB}$ among overweight and obese patients compared to those with normal weights [69]. There is more evidence needed to confirm the findings. More recent data have also provided detailed evidence of the mechanisms involved. A narrative review of studies in humans and animals demonstrated the negative impact of various macro- and micronutritional deficiencies on TB immunity. Although the exact biological pathways are not fully understood, it is clear that poor nutrition, and specifically protein deficiency, impedes the ability of the cell-mediated immune system to fight $M$. tuberculosis, as it does for other infections [17]. Malnutrition is an important contributing factor to TB on a population level, especially in poor countries (table 1). Low BMI at the time of diagnosis has also been linked to risk of treatment failure, death during TB treatment and relapse [70-72].

\section{Silicosis}

The association between silicosis and pulmonary TB has been well documented. Silicosis is caused by the inhalation of crystalline silica particles, almost always due to occupational environments, including mining, sandblasting, quarrying, ceramic working and iron smelting [73]. Studies in South Africa showed RRs of developing pulmonary TB between 2.8 and 4.7, depending on the grade of silicosis [74, 75]. A large case-control study in the USA found a mortality OR for pulmonary TB of 39.5 among silicotics [76], but most of the work around silicosis and TB has focused on occupational risk groups (e.g. miners) and has not looked at silicosis as a risk factor for poor TB outcomes. There is evidence of an increased case-fatality rate [77], but silicosis and silica dust exposure are not deemed risk factors for relapse or reinfection [78].

\section{Other NCD}

Although there have been few studies to document any causal relationships between mental illness and $\mathrm{TB}$, they can, in theory, negatively impact the cell-mediated immune system, which may put the M. tuberculosis-infected patient at increased risk for developing TB. The role of mental disorders, both in contracting $M$. tuberculosis infection though physical location (homeless shelters, hospitals or other congregate settings) and TB through the plausible biological pathway discussed by PRINCE et al. [79] in an article of mental disorders and links with other disease is not well described, but is conceivable. A systematic review of the literature on this topic could help better describe the relationships. However, there are strong links between economic and social burdens of TB, especially in its more severe forms, leading to alcohol abuse, malnutrition and depression [43, 80-82].

Cardiovascular diseases have links with TB, but they have not been documented as direct risk factors for $\mathrm{TB}$, but rather, $\mathrm{TB}$ sequelae have been known to be a risk factor for cardiopulmonary failure [83]. Other chronic conditions, such as autoimmune and systematic disorders, chronic renal failure, liver failure, certain malignancies and a wide range of immunosuppressant treatments, are also associated with TB $[14,84-88]$. It is essential to keep TB in mind during clinical management of these conditions, especially in high-TB burden settings, even though they are less important from a public health viewpoint, due to relatively low prevalence.

\section{IMPLICATIONS FOR CASE-DETECTION STRATEGIES}

Programmatic TB case-detection activities, under the Stop TB Strategy, have mainly focused on "passive case finding" approaches, i.e. waiting for patients with symptoms to present 
to health services and then screening those with chronic cough for TB (usually defined as cough for a duration of more than 2-3 weeks) $[89,90]$. Although the expansion of DOTS has led to impressive gains in the proportion of the estimated incident cases detected (from 10\% in the early 1990s to $61 \%$ in 2008), the rates of increase have flattened over the past $5 \mathrm{yrs}$, and the former $70 \%$ case detection rate target, set by WHO for 2005, has yet to be achieved [23]. Additionally, it is unlikely that reaching the $70 \%$ target will be sufficient to generate the decline in TB incidence expected when the targets were set. The global target has now been made more ambitious, with an ultimate goal to achieve as close as possible to universal case detection [18]. Early case detection, which includes the removal of infectious cases out of the prevalent pool as soon as possible, is essential to cut transmission effectively. It is also important to alleviate suffering and improve the chance of cure for the individual patient. To meet these goals, more intensified and prioritised case-detection strategies will be needed, and active screening among risk groups is one potential approach.

The adoption of targetted screening for latent infection and its treatment in certain groups have been done in certain settings, primarily in Europe and the USA, as well as other countries where TB prevalence is quite low, and there is a move towards elimination. While this article focuses on detection and management of active TB, screening and treatment of latent M. tuberculosis infection may be useful in certain groups. Isoniazid preventive therapy (IPT) has been promoted for HIVinfected people after screening for $\mathrm{TB}$, due to the high risk of developing TB if HIV-infected [25]. Patients with identified NCD will also benefit from IPT, but the number of treatments to avoid an incident TB case would theoretically be greater, due to the different RRs. Currently, there is little documentation about the benefits of IPT in patients with NCD, but it may be beneficial for programmes currently providing IPT to screen NCD patients for latent TB infection.

TB is more common among people with the NCDs discussed here than among the general population. Therefore, more active screening for TB among them would, in principle, help increase TB case detection. However, it is not clear what screening strategy may be most effective, feasible and affordable. There are a number of potential strategies that clinicians and public health managers may use to ensure early diagnosis among people with NCDs, but four main considerations should be made before pursuing them as follows. 1) What will the yield be? 2) Is it practical to reach the risk group? 3) Is it cost effective? 4) Is it affordable?

The decision of which groups to actively screen may be very different depending on local TB epidemiology, health system context and clinical setting. Moreover, for individual patient management, the considerations for clinical decision-making may look very different from the decision tree for public health interventions. Nevertheless, it seems reasonable that in all medium-to-high TB burden settings, heightened awareness among clinicians about these NCDs as risk markers for TB is important in order to ensure early diagnosis and optimal individual care. Table 2 summarises some of the observations for the different NCDs discussed in this paper.

\section{Yield of screening activities among patients with NCD}

Figure 1 presents a theoretical model that can be used to help guide programmatic decisions about which groups to target for screening. The yield of such strategies will depend on the sensitivity of the screening approach, the RR for TB associated with each risk factor, the prevalence of the risk factor, the TB prevalence and the case-detection gap in a specific risk group in a given setting. The variability even within a single risk factor is demonstrated by the findings that the number of diabetes patients needed to screen to detect one TB case ranged from four in Korea to 100 in Hungary, while the number of those needed to be followed-up to identify a TB case within 1 yr ranged from 152 in Tanzania to 1,000 in Ethiopia [40]. Different approaches may thus be considered depending, for example, on TB and NCD prevalence, TB case-detection gap and healthcare resources in a given setting.

Most COPD patients meet the TB suspect definition. However, chronic coughers more often than not pass through health facilities without being screened for TB, especially in low-TB prevalance settings [91-93]. All COPD patients could receive periodic screening to rule out TB and clinicians can probably increase the diagnosis of both diseases by actively screening TB patients for COPD and vice versa, as advocated within WHO's Practical Approach to Lung Health, for which there are comprehensive guidelines [94]. COPD is common in some populations $(4-10 \%$ of adults in various countries where it has been measured rigorously) [95], and the potential yield may therefore be large if people with COPD in high-TB burden settings are screened systematically. Prevalence of COPD is much lower than the prevalence of smokers, which was about $30 \%$ overall and 38\% in European males as of 2002. Furthermore, $\geqslant 11$ Eastern European countries have prevalence rates $>50 \%$ [96]. Screening all smokers for TB would potentially give an even higher yield, but feasibility and costeffectiveness would be much lower, as smokers in general would be harder to reach than people diagnosed with COPD (see discussion about practicality later).

The estimated prevalence of heavy drinking is $>15 \%$ among adults in Europe [97], and the prevalence of alcoholism among TB patients is $\sim 50 \%$ in some countries [29]. Heavy drinking and alcohol-use disorder might account for nearly $35 \%$ of pulmonary TB in central European countries (table 1). This therefore represents a significant risk group in some countries, and screening for TB among alcoholics may potentially yield significant numbers. However, as for smoking, COPD and DM, we do not have good evidence showing the feasibility and costeffectiveness of systematic screening in these groups.

\section{Practicality of screening}

\section{Diabetes mellitus}

Some populations are quite difficult to reach and screen through both public health approaches and at a clinical level due to lack of specific services for them (smokers and the malnourished), while others are much more easily identified as a group (known diabetics, people with diagnosed COPD, silicotics and mentally ill people). DM patients should be seen regularly at healthcare facilities where they could be screened for TB upon diagnosis and periodically while diabetes is being managed. Although DM with poorly controlled blood sugar levels has been identified as a risk factor for TB, the best 


\begin{tabular}{|c|c|c|c|c|}
\hline NCD & Case-detection strategies & $\begin{array}{l}\text { Case-management } \\
\text { implications }\end{array}$ & NCD reduction & Research priorities \\
\hline DM & $\begin{array}{l}\text { DM patients are regularly seen } \\
\text { at health care facilities where they } \\
\text { can be screened for TB upon } \\
\text { diagnosis and periodically while } \\
\text { the DM is being managed. }\end{array}$ & $\begin{array}{l}\text { TB drug hepatotoxicity } \\
\text { might increase } \\
\text { DM is somewhat associated } \\
\text { with delay in sputum culture } \\
\text { conversion at 2-3 months } \\
\text { May increase death } \\
\text { during TB treatment } \\
\text { May increase risk of MDR-TB }\end{array}$ & $\begin{array}{l}\text { Better control and } \\
\text { management of DM } \\
\text { Exercises and diet }\end{array}$ & $\begin{array}{l}\text { The best screening methods } \\
\text { have not been identified. } \\
\text { The optimal time to screen for } \\
\text { DM needs to be specified and the } \\
\text { definitions should be standardised. } \\
\text { Impact of interventions on TB } \\
\text { outcomes }\end{array}$ \\
\hline Smoking and COPD & $\begin{array}{l}\text { Hard to systematically screen } \\
\text { smokers but may seek care } \\
\text { more often and it can heighten } \\
\text { awareness for TB screening } \\
\text { COPD patients may be } \\
\text { periodically screened as they } \\
\text { meet TB definition and COPD } \\
\text { is a independent risk factor }\end{array}$ & $\begin{array}{l}\text { Linked to severity of TB at the } \\
\text { time of diagnosis, risk of } \\
\text { relapse and higher risk of } \\
\text { death from TB than nonsmokers } \\
\text { Unclear if COPD is a risk factor for } \\
\text { TB, independently from smoking. } \\
\text { However, TB seems to be an } \\
\text { independent risk factor for COPD }\end{array}$ & $\begin{array}{l}\text { National policies } \\
\text { including taxes } \\
\text { Smoking cessation } \\
\text { interventions }\end{array}$ & $\begin{array}{l}\text { The best screening methods } \\
\text { have not been identified. } \\
\text { Impact of interventions on } \\
\text { TB outcomes } \\
\text { Effectiveness of tobacco } \\
\text { cessation among TB patients }\end{array}$ \\
\hline Alcohol use $>40 \mathrm{~g} \cdot$ day $^{-1}$ & $\begin{array}{l}\text { Hard to systematically screen but } \\
\text { may seek care more often and it } \\
\text { can heighten awareness for } \\
\text { TB screening }\end{array}$ & $\begin{array}{l}\text { Added importance of DOTS } \\
\text { TB drug hepatotoxicity might } \\
\text { increase with DM and alcohol } \\
\text { use disorder. } \\
\text { Significant decreases in absorp- } \\
\text { tion of isoniazid and its acceler- } \\
\text { ated metabolism after oral } \\
\text { administration to heavy drinkers } \\
\text { Effective treatment strategies } \\
\text { for alcohol reduction exist }\end{array}$ & $\begin{array}{l}\text { National policies } \\
\text { including taxes } \\
\text { Alcohol reduction } \\
\text { programmes }\end{array}$ & $\begin{array}{c}\text { The links between alcohol use } \\
\text { and TB outcomes, and y } \\
\text { acquired drug resistance } \\
\text { The best screening methods } \\
\text { have not been identified. } \\
\text { Impact of interventions on } \\
\text { TB outcomes } \\
\text { Effectiveness of brief interventions } \\
\text { on alcohol use disorders }\end{array}$ \\
\hline Mental illness & $\begin{array}{l}\text { Mentally ill people are seen } \\
\text { regularly at health care facilities } \\
\text { and can be screened for TB } \\
\text { and offered chemotherapy }\end{array}$ & $\begin{array}{c}\text { Added importance of DOTS } \\
\text { Drug interactions must be } \\
\text { considered } \\
\text { Social support }\end{array}$ & $\begin{array}{l}\text { Social support mechanisms } \\
\text { Stigma reduction }\end{array}$ & $\begin{array}{l}\text { Better establish links between } \\
\text { mental illness and TB disease } \\
\text { Feasibility of screening and } \\
\text { early case detection } \\
\text { Feasibility of IPT }\end{array}$ \\
\hline
\end{tabular}

DM: diabetes mellitus; COPD: chronic obstructive pulmonary disease; TB: tuberculosis; MDR: mutidrug-resistant; DOTS: directly observed treatment, short course; IPT: isoniazid preventative therapy.

screening methods have not been identified. Additionally, the optimal time to screen for DM needs to be specified, as the inflammatory process associated with $\mathrm{TB}$ may results in a temporary hyperglycaemia, which can produce false positive results for DM, and the definitions should be standardised.

\section{Alcohol abuse and tobacco use}

In clinical settings, a heightened awareness of TB symptoms could be employed with active screening for TB symptoms among patients with known or suspected alcohol abuse and/ or smoking. Although smokers as a general population are difficult to reach, they probably seek care more often than nonsmokers [98], and opportunities to engage and screen smokers for TB symptoms should not be missed. A high index of suspicion for TB among patients who smoke and among those who present with other risk factors for TB (contacts, COPD, alcohol use, etc.) can increase case detection.

\section{Malnutrition}

When undernourished people are identified by health services, this should alert clinicians to actively probe for TB symptoms, especially in medium-to-high TB prevalence settings. 
To improve TB case detection

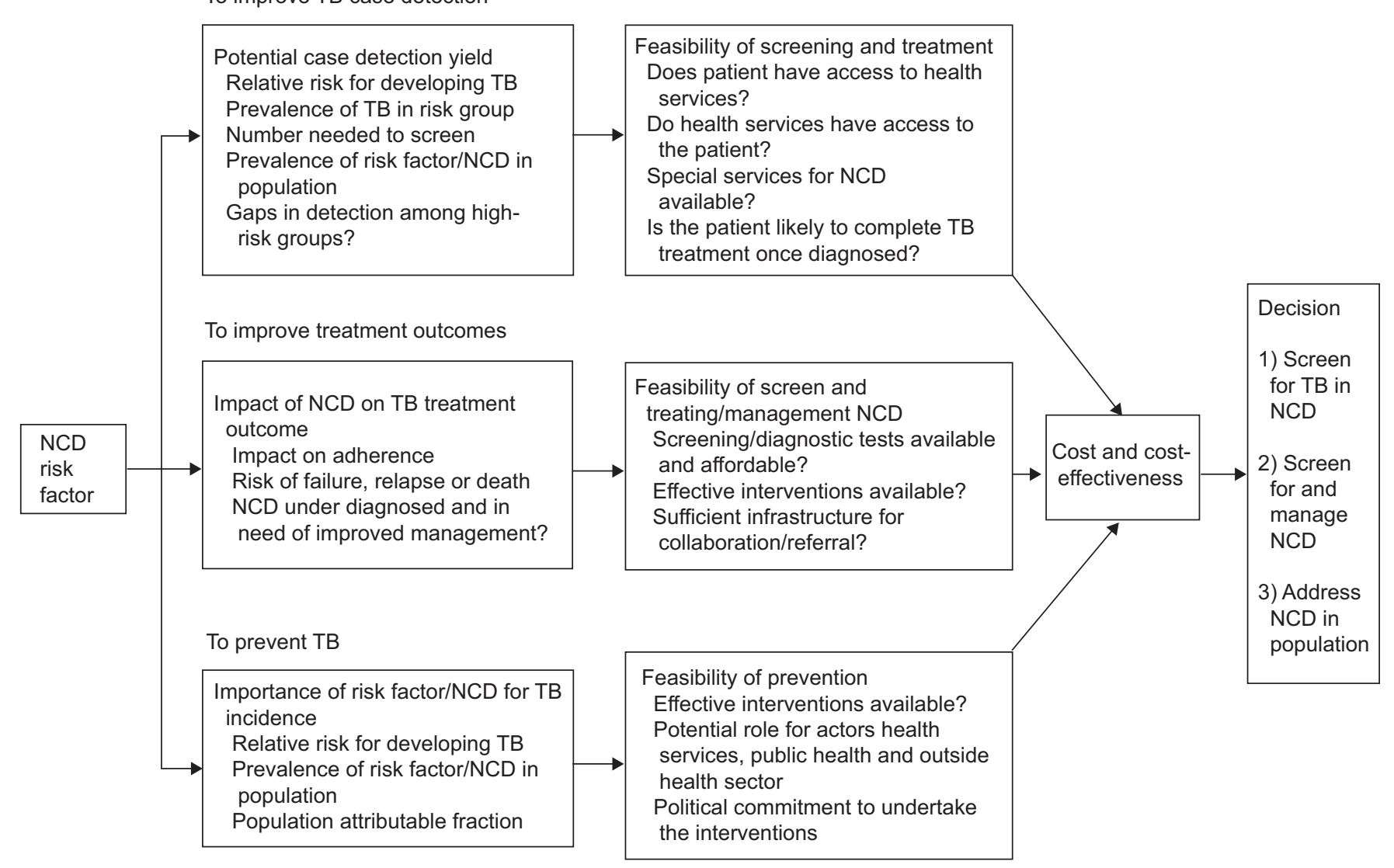

FIGURE 1. Decision framework for targeting noncommunicable disease (NCD) risk groups for tuberculosis (TB) case detection, management and prevention.

However, comprehensive screening of this group on population level is challenging. Population-based case finding measures targeting the undernourished are probably better off focusing on proxies, such as urban slum dwelling and homeless shelters. In US settings, a few studies have found low yield in homeless shelters due to low participation rates, rather than low prevalence $[99,100]$. In Brazil, more success has been achieved in screening at-risk groups in these populations. Two studies in Sao Paulo showed that large populations in shelters and prisons could be screened in short periods of time with fairly good yield [101, 102].

\section{Silicosis}

Even though the relationship between TB and silicosis is well documented, a study in Spain found that presence of silicosis was an independent risk factor for health system delay in diagnosing and treating patients with TB [103]. This may be due to the fact that the diagnosis of TB among silicotics can be very difficult, especially in lower grades, when the clinical manifestations can be benign and the radiological alterations can be indistinguishable from those resulting from the preexisting silicosis [104]. Patients with known occupational exposure to silica can be monitored continuously for both TB and silicosis.

Clinicians seeing patients with certain of the NCDs described here, as well as other less prevalent ones, which require administration of immunosuppressant therapies should be closely monitored, especially in high-TB burden settings, as many of these conditions put patients at increased risk of developing TB [57].

\section{Costs and cost-effectiveness of intensified case finding}

Although data on the costs of TB control show both that it is an effective intervention in terms of disability-adjusted life-yrs saved [105] and that investments in TB will actually create a return on investment [106], there have been few studies looking at the cost-effectiveness of screening initiatives. Part of the reason for this is that passive detection was promoted as the most cost-effective and efficient approach for developing countries [107]. While national programmes are certainly still restricted in terms of resources, there are more funding opportunities for new ways to reach cases that have not been captured under the basic approaches used in the past. At the same time, there is a growing realisation that it may cost more to detect the harder-to-reach cases, as well as to diagnose TB early. A review of historical active case-finding approaches among high-risk groups found that while there was good evidence that several interventions were feasible and generated additional detection of TB cases, there has been little analysis of how this affected transmission and TB incidence. Additionally, few rigorous cost-effectiveness analyses have been done [108]. While increased screening of people at higher risk of TB will certainly be more expensive than the current passive approach, it is not unrealistic to believe that intensified detection activities among certain risk groups may have good 
yields, as well as possibly increasing early case detection. However, more research is required to demonstrate epidemiological impact, cost-effectiveness and affordability.

\section{CLINICAL MANAGEMENT STRATEGIES}

While there has been a focus on HIV-associated TB, national TB programmes have paid little attention to proper management of noncommunicable TB comorbidities. This may be due to many reasons, including not diagnosing the comorbidity, weak existing services for NCDs, poor coordination between disease programmes, lack of desire within TB programmes to take on other conditions and lack of awareness about the necessary steps to take. There are a number of strategies that can be employed to help ensure better diagnosis, case management and outcomes for patients with comorbidities. Just as patients with risk factors for TB should be screened for active disease, TB patients should be screened for NCD comorbidities as and when indicated. During TB treatment, optimised TB management, with strict supervision when required, should be employed. Likewise, careful NCD management is vital to overall good health outcomes. Finally, risk groups may require monitoring after cure, to check regularly for TB relapse. Table 2 summarises some of the observations for the different NCDs discussed here.

\section{Optimal TB treatment and support}

All TB patients should have close TB treatment supervision combined with appropriate patient support mechanisms, as outlined in the Stop TB Strategy and the International Standards for Tuberculosis Care [23, 109]. This becomes especially important for some patients with NCDs who are at higher risk for poor treatment outcomes, such as people with alcohol-use disorder, smokers and undernourished patients. For example, alcohol use is a strong risk factor for treatment interruption [41]. Some studies have found an association between drug resistance and alcohol dependence, but it is unclear if it is because of adherence issues or as a risk factor due to other social interactions [110, 111]. Studies of the pharmacokinetics of isoniazid in the treatment of TB patients with alcohol dependence have shown significant decreases in absorption of the drug and its accelerated metabolism after oral administration to heavy drinkers [112]. A review of studies on the pharmacokinetic relationship between DM and TB medications showed that apart from glipizide, DM medications had reduced pharmacokinetic parameters in subjects administered rifampicin [40]. There is a knowledge gap on the interactions between DM medications and other TB drugs. Additionally, there is some evidence that rifampicin levels may be reduced among DM patients due to malabsorption [113]. This may have important implications, resulting in poor DM control in patients who are administered TB treatment regimens that include rifampicin, as well as implications for $\mathrm{TB}$ treatment with regimens containing rifampicin among diabetics. TB drug hepatotoxicity might also increase with DM and alcohol-use disorder [114, 115]. Peripheral neuropathy is associated with both isoniazid use and certain NCDs, including DM (especially if glucose levels are poorly controlled), alcohol-use disorder, malnourishment (specifically vitamin deficiencies) and certain autoimmune disorders. Close monitoring of patients with these NCDs on IPT is warranted. Finally, patients beginning treatment with poor nutritional status are at risk for poor outcomes [17]. Optimal TB treatment is, therefore, required for these patients, especially since standard TB treatment has been shown to be a great mediator for return to normal nutritional status [72].

It is, thus, clear that the standard TB treatment and management approach recommended by WHO should be optimised in these particularly vulnerable groups. Understanding the possible interactions and complications of TB treatment due to factors such as DM, alcohol-use disorder, undernutrition and smoking should improve clinical care and focus attention to the specific TB treatment needs of those patients. Critically, the strict application of DOTS, enhanced clinical monitoring and optimal patient support structures need to be considered for these patients.

It is much less evident that TB treatment regimens need to be changed in people with certain NCDs. It is common clinical practice in some settings to extend the TB treatment duration in people with diabetes. In 13 studies reviewed in the expert meeting on TB and DM, the results suggested that DM has a minor effect on TB treatment success [14]. However, this is somewhat contradicted by some findings that diabetes may be associated with delay in sputum culture conversion at 2 3 months of TB treatment, may increase death during TB treatment and relapse, and may have a relationship with MDR$\mathrm{TB}$, although the findings are not strong and more evidence is needed [40]. No trial on the effectiveness of extended treatment duration has been published. Nonetheless, the US Centers for Disease Control and Prevention are developing guidelines for Pacific Islanders that consider extending $\mathrm{TB}$ treatment to 9 months (R. Brostrom, Centers for Disease Control; personal communication), while emphasising that this is based on clinical experience only, and pointing out that additional research is required to determine if prolonged treatment actually improves treatment outcomes and/or reduced risk of relapse or acquired drug resistance.

\section{Screening and managing NCDs in TB patients}

Screening for NCDs allows the TB clinician to provide better general care for TB patients, so that TB outcomes, as well as general health outcomes, can be optimised. For all of these comorbidities, providers should be coordinating closely with other specialties and other disease programmes to ensure the best diagnostic approach and care for the patient. There is at least one example of HIV/AIDS programmes linking with chronic disease clinics to provide integrated care, and TB programmes could do the same [116]. Linking patients with other departments for management of comorbidities has been shown to improve TB/HIV collaboration [44, 117] and depending on the circumstances, having TB programmes work more closely with NCD units or programmes will be helpful. Based on the experience from TB/HIV collaboration, asking a substance abuse clinic or diabetes clinic to systematically screen patients for TB should be more easily accepted if the TB programme can contribute to alcohol-use disorder and DM case finding and management.

The DOTS approach offers some opportunities for optimal management also of NCDs. Potentially, clinicians can also use the DOTS approach for standardisation and treatment support for NCDs. A recent proposed framework to improve primary 
care in NCDs also explores the potential benefits that can be realised by adapting delivery systems to help identify, manage and prevent NCDs at the primary care level [118]. By employing a well developed and tested strategy to help control NCDs, healthcare systems may be able to provide better care to patients with both chronic and acute conditions, and help alleviate the double burden of infectious and chronic disease. A good example of this possibility is for DM. Regular interaction with the health service and/or outreach health workers/volunteers for TB treatment, especially in the intensive treatment phase, provides excellent opportunities to provide health education and behaviour change messages for improved diabetes management $[119,120]$. Since poor glucose control is associated with higher risk of $\mathrm{TB}$, it is plausible that it is also associated with poorer treatment outcomes and risk of relapse, though the direct evidence for this is lacking. Nevertheless, optimising DM management during TB treatment should be a high priority for improving the general health status of the patient, especially as TB can aggravate DM and worsen glucose control. Similar arguments can be made for alcohol abuse and smoking.

Interventions in clinical settings have shown to have a positive impact in different settings for reducing heavy drinking [121123] and effective treatments for severe alcohol dependence have been described [124]. Appropriate measures should be routinely offered to those screened positively for heavy alcohol use and alcohol-use disorder, especially in settings where a high proportion of TB patients are alcohol-dependent. As alcohol-use disorders can cause the deterioration of living conditions that are both social and financial in nature, as well as impact TB treatment outcomes, addressing the condition may be the key for successful treatment [125, 126].

Interventions for smoking are widespread, with varying degrees of success [127]. Simple smoking cessation programmes in clinical settings can be effective and quite costefficient, although simple training for clinicians will likely not be sufficient for a larger impact $[128,129]$. One study in Sudan has demonstrated that it was feasible to implement a largescale smoking cessation programme within TB services despite the workload of local staff and produce positive results for TB treatment success as well as smoking cessation [130]. Enrolment in smoking cessation programmes can help and will certainly benefit the overall health of the patient. Information and education should be used to curb the activity as much as possible.

Although nutritional support during TB treatment is often recommended, there is little evidence on the effectiveness of such support for TB-specific outcomes. A Cochrane review found limited evidence for the use of dietary supplements as a means for improving TB treatment outcomes, but recommended further research, as the evidence base was found to be very thin [131]. While awaiting more data, it is important to recognise that there is clear evidence that nutritional support is important for nutritional rehabilitation and general quality of life [132]. In addition, food support can act as an enabler for TB diagnosis and treatment completion [133]. However, though many countries have had large-scale programmes to provide nutritional support to TB patients, there have been very few rigorous evaluations to determine the best type of nutritional support, the best way to deliver it, whether it should be directly for the patient or for the family, and in what setting [134].

There is no specific treatment for silicosis that is efficient and based on clinical trials. Managing TB patients with silicosis demands early diagnosis of both diseases [46]. There is very limited evidence that tetrandrine may improve pulmonary function and delay disease progression [135]. As most TB providers are not skilled in managing mental illness, comorbidity with such disorders can be quite challenging. Depression, for example, has an important effect on adherence to treatment for many health conditions but there are few studies that have investigated these associations [79]. This underscores the importance of close collaboration with other specialities and programmes.

\section{PREVENTING TB BY ADDRESSING NCD}

Addressing the NCDs that are risk factors for TB can strengthen efforts to prevent TB in a number of ways. First, improving diagnosis of NCD among TB patients and better coordination with NCD services for patient management could diminish the risk of future TB recurrence (relapse or reinfection). However, addressing NCDs in people with TB only would affect just a small fraction of all people with these conditions. The preventive impact would be greater if $\mathrm{TB}$ programmes and TB specialists would facilitate better diagnosis, care and prevention of these conditions throughout the health system and beyond. TB control programmes in many countries have been decentralised and integrated into primary health centres. They see patients at a much more peripheral level then some more specialised services that provide NCD management. By contributing to screening efforts for NCDs, TB programme-affiliated staff can contribute to better collaboration, early NCD diagnosis and overall health systems strengthening through the spread of primary care services to a larger population, which is a major goal for WHO [136].

Secondly, and more significantly, population-level interventions aimed at reducing the prevalence of NCDs would potentially have a dramatic impact on $\mathrm{TB}$ incidence and prevalence. The population attributable fractions of these risk factors are significant, and in many European countries, the population attributable fractions of NCD are much higher than for HIV (table 1). The differences among regions as to which risk factors to prioritise can vary significantly, although only in one region is HIV the leading risk factor. Malnutrition probably contributes heavily to the TB burden in many regions and is the strongest factor in three of the WHO regions listed in table 1. Many of the NCDs discussed here are modifiable through behavioural changes, and through policy and regulatory interventions. For example, there is ample evidence that taxes and policy changes, including marketing restrictions, and limiting the availability of alcohol and tobacco, can reduce consumption $[16,137,138]$. These policy changes may not only have positive effects on the incidence of $\mathrm{TB}$, but on health in general and the costs of medical care [139].

Thirdly, although out of reach for many national TB control programmes and NCD control programmes, larger efforts to address the social determinants common to both TB and NCD will have a positive impact on both as well as a larger impact on the overall population health [32]. The improvement in 
nutritional status on a population level, along with better living conditions and other social advances, has been suggested as a partial cause of the enormous TB incidence decline in Europe in the 20th century. Promoting better food security and support for the general population, and certainly for those in most need, can have a large impact on TB control. Eastern European and former Soviet Union countries experienced a rapid increase in TB incidence in the 1990s [140, 141] that can be traced to the erosion of health and social support systems, as well as a rise in conditions such as alcohol-use disorders. If left unchecked, increasing prevalence of NCD can have an impact on TB and vice versa.

\section{IMPLICATIONS FOR TB CONTROL PROGRAMMES}

National TB control programmes and NCD programmes are already overburdened and understaffed, especially in resource-poor countries. Adding NCD diagnosis and management to the TB agenda, and vice versa, may be perceived as overwhelming by many programmes. However, better coordination and some pooling of resources may create mutual benefits. More active screening for both TB and NCD will help management of the patient and treatment outcomes through comprehensive identification of treatment and support needs. Better coordination with specialists and other care providers will improve overall patient health.

Reaching out to other disease programmes and providers is something that national TB control programmes have traditionally not done well, but the experiences of MDR-TB and TB/HIV management provide two good examples of how working with other programmes can strengthen the programme. These lessons may be used for collaboration between NCD and TB programmes.

The intense focus on MDR-TB and TB/HIV over the last 1015 yrs and how best to support such patients can provide some good examples of how basic TB control programmes can strengthen themselves by working outside the programme. MDR-TB represents a failure to effectively treat TB patients inand outside of TB programmes. The steps that have been taken to rectify these failures for MDR-TB have been impressive and necessary. For instance, patient support groups are seen as an important factor for successful treatment outcomes, as the mental-health issues surrounding MDR-TB have received good attention [43]. Some MDR-TB programmes have developed strong links with substance dependency interventions while recognising that there is a limited arsenal of $\mathrm{TB}$ drugs to combat the disease, and substance abuse can hinder adherence and drug absorption [142]. The guidelines for treating comorbidities for MDR-TB patients are more developed than for drug-susceptible TB patients, due to the importance of drug interactions in various comorbidities and the effect on treatment outcomes these possess [143, 144]. Although standardised treatment for pan-sensitive TB has been very successful, there are still questions about how to best manage certain patients, such as those with diabetes, alcohol and drug dependency, and mental illness. Using the models of some MDR-TB programmes to better engage other programmes is an opportunity for TB control programmes to impact the health of patients across disease areas, and contribute to health system strengthening and better overall care.
In TB/HIV care, WHO has launched a number of initiatives that recognise the importance of the two disease programmes working together to address the dual epidemics. In 2004, the WHO Stop TB and HIV/AIDS departments released basic suggestions for how to better integrate TB and HIV care and treatment. It has helped scale-up of HIV testing among TB patients, which has increased more than seven times since 2002, and reported TB testing among HIV-positive patients has been even more dramatic [145]. The other measures in the 12-point package for better cooperation include HIV prevention and TB infection control, which aim to reduce the continued spread of the diseases. The generic elements of improved collaboration may be applicable for collaboration with other public health programmes as well, including those dealing with NCDs.

While the relationship between NCD and TB is complex and requires more careful attention and research, it certainly presents an opportunity for strengthening both areas in health service delivery, as well as for achieving the larger goal of general health system strengthening. With progress towards global case detection of TB stalled [18], there is growing recognition that more intensive case-detection efforts are needed and that quality of treatment and overall case management need be further improved. The status quo in the casedetection trend, the limitations of the "passive case finding" approach and the slow decline in TB burden globally call for intensified action, including more attention to TB risk groups in general, and TB-related NCDs in particular [44, 146, 147]. However, the feasibility, costs and cost-effectiveness of required interventions have not been well documented, and more research is needed before judging which risk groups to target and how. What is clear is that clinicians need to be especially alert to identify conventional TB-screening indications in people with risk conditions.

This review provides some arguments for systematic and active screening in special clinical groups that can be easily identified and reached. This may include people with diabetes, silicosis, alcohol-use disorder, undernourished people and/or people with COPD, depending on the health system set-up and capacity, as well as on the local epidemiological situation. If urban slums or other defined vulnerable groups can be used as a proxy for malnourishment, poor health in general and high exposure to other risk factors, such as poor access to care, crowding, other infections, etc., they also may present good opportunities to increase TB case detection, as indicated by a recent study [148]. In certain nonhealthcare settings, such as homeless shelters, prisons, and social institutions, active case finding among alcoholics may prove useful.

While standardised TB treatment regimens have been able to effectively treat $\geqslant 85 \%$ of $\mathrm{TB}$ cases globally, unsuccessful treatment outcomes are high (33\%) in the European region, which is often related to drug resistance, weak health systems and access problems $[18,23]$. Additionally, many of the NCDs discussed in this paper put patients at higher risk of poor outcomes and are highly prevalent in the European region. Optimised TB treatment, management and patient support are the first essential measures in people with comorbidities associated with poor treatment outcomes. Improved management of the comorbidities themselves is the next logical step, which should improve both TB outcomes and general health. 
These clinical interventions should be combined with public health policy measures aimed to prevent NCDs and TB. The NCDs discussed in this article can be addressed through combinations of behavioural change interventions, policy, regulation, taxation, environmental action and structural interventions to address underlying social determinants. Such interventions largely lie outside the purview of health service providers, but are essential elements of the broader public health agenda. Although they may not be well suited to take the lead, TB programmes and clinicians working in TB care should play important roles in the process, at least as advocates. There are increasingly more models showing how TB programmes can reach outside what have traditionally been disease-specific systems, and in the future, with increasing focus on primary healthcare and health system strengthening, collaborative efforts will be necessary, as evidenced by recently developed frameworks for $\mathrm{TB} / \mathrm{HIV}$, and $\mathrm{TB}$ and smoking [127, 136].

\section{RESEARCH PRIORITIES}

Although the NCD-TB link has received attention in recent years, there are many questions that need to be addressed. Better data are needed to guide policy decisions on priority actions to intensify case detection, including better estimates of precision, potential yield, impact on early case detection, costeffectiveness, and feasibility of different screening and diagnostic approaches in different target groups. Better evidence to answer questions such as the profile of patients who should receive screening for $\mathrm{TB}$, which risk factors, at what intervals, and using what screening and diagnostic tools is lacking and should be the subject of future research. More research will need to be conducted on the impact that smoking cessation has on treatment outcome in smokers, and what the impact is of glycaemic control on the outcomes of diabetic patients with TB. Systematic reviews in areas such as mental health and TB should be undertaken to better document the knowledge base and gaps. A systematic review of the many studies looking at TB treatment indicators, such as culture conversion, death and relapse, is also needed to help guide policy and management. More investigations are also needed to evaluate programmatic and managerial aspects of improved collaboration between TB and NCD interventions and programmes. Ultimately, in order to plan appropriate action, each country also needs to map out the main TB risk factors, the distribution, availability and quality of health services for concerned NCDs, and opportunities for improved coordination.

\section{CONCLUSIONS}

The growing burden of NCD has important implications for TB epidemiology, TB case management and TB treatment outcomes. Several NCDs put people at increased risk for $M$. tuberculosis infection and weaken immune responses, which increases risk for TB. Some of them can make detection more difficult, affect TB drug effectiveness, worsen the general conditions of the patient, worsen treatment adherence, and increase the risk of treatment failure, TB recurrence and death. At the same time, these diseases and conditions are preventable and treatable. TB programmes and clinicians treating TB must work more closely with those in general health services providing prevention and care for NCDs, within the context of primary care and the general health system. Ultimately, the many opportunities for improved collaboration, which will strengthen control efforts in both communicable disease and NCD control, will need to be exploited to provide the best care and have a greater impact on both TB and NCD control.

\section{SUPPORT STATEMENT}

J. Creswell, M. Raviglione, S. Ottmani, M. Uplekar, L. Blanc and K. Lönnroth are staff members of the World Health Organization (WHO). The authors alone are responsible for the views expressed in this publication and they do not necessarily represent the decisions or policies of the WHO. The research was funded by the WHO.

\section{STATEMENT OF INTEREST}

None declared.

\section{REFERENCES}

1 Gaziano TA. Cardiovascular disease in the developing world and its cost-effective management. Circulation 2005; 112: 3547-3553.

2 Miranda JJ, Kinra S, Casas JP, et al. Non-communicable diseases in low- and middle-income countries: context, determinants and health policy. Trop Med Int Health 2008; 13: 1225-1234.

3 Mayosi BM, Flisher AJ, Lalloo UG, et al. The burden of noncommunicable diseases in South Africa. Lancet 2009; 374: 934-947.

4 Abegunde DO, Mathers CD, Adam T, et al. The burden and costs of chronic diseases in low-income and middle-income countries. Lancet 2007; 370: 1929-1938.

5 Ramaraj R, Alpert JS. Indian poverty and cardiovascular disease. Am J Cardiol 2008; 102: 102-106.

6 van Zyl Smit RN, Pai M, Yew WW, et al. Global lung health: the colliding epidemics of tuberculosis, tobacco smoking, HIV and COPD. Eur Respir J 2010; 35: 27-33.

7 Slama K. Global perspective on tobacco control. Part I. The global state of the tobacco epidemic. Int J Tuberc Lung Dis 2008; 12: 3-7.

8 Laniado-Laborín R. Smoking and chronic obstructive pulmonary disease (COPD). Parallel epidemics of the 21 century. Int $J$ Environ Res Public Health 2009; 6: 209-224.

9 Hossain P, Kawar B, El Nahas M. Obesity and diabetes in the developing world: a growing challenge. N Engl J Med 2007; 356: 213-215.

10 Rahman A, Prince M. Mental health in the tropics. Ann Trop Med Parasitol 2009; 103: 95-110.

11 Patel V. Mental health in low- and middle-income countries. $\mathrm{Br}$ Med Bull 2007; 81-82: 81-96.

12 Patel V, Araya R, Chatterjee S, et al. Treatment and prevention of mental disorders in low-income and middle-income countries. Lancet 2007; 370: 991-1005.

13 World Health Organization. Closing the Gap in a Generation: Health Equity Through Action on the Social Determinants of Health. Final Report of the Commission on Social Determinants of Health. Geneva, World Health Organization, 2008.

14 Jeon CY, Murray MB. Diabetes mellitus increases the risk of active tuberculosis: a systematic review of 13 observational studies. PLoS Medicine 2008; 5: e152.

15 Lönnroth K, Williams BG, Stadlin S, et al. Alcohol use as a risk factor for tuberculosis: a systematic review. BMC Public Health 2008; 8: 289.

16 Lin HH, Ezzati M, Murray M. Tobacco smoke, indoor air pollution and tuberculosis: a systematic review and metaanalysis. PLoS Medicine 2007; 4: e142.

17 Cegielski P, McMurray DN. The relationship between malnutrition and tuberculosis: evidence from studies in humans and experimental animals. Int J Tuberc Lung Dis 2004; 8: 286-298. 
18 Lönnroth K, Castro K, Chakaya JM, et al. Tuberculosis control and elimination 2010-50: cure, care, and social development. Lancet 2010; 375: 1814-1829.

19 World Health Organization. Global Health Risks: Mortality and Burden of Disease Attributable to Selected Major Risks. Geneva, World Health Organization, 2009.

20 Sotgiu G, Ferrara G, Matteelli A, et al. Epidemiology and clinical management of XDR-TB: a systematic review by TBNET. Eur Respir J 2009; 33: 871-881.

21 Migliori GB, Besozzi G, Girardi E, et al. Clinical and operational value of the extensively drug-resistant tuberculosis definition. Eur Respir J 2007; 30: 623-626.

22 Migliori GB, Loddenkemper R, Blasi F, et al. 125 years after Robert Koch's discovery of the tubercle bacillus: the new XDRTB threat. Is "science" enough to tackle the epidemic? Eur Respir J 2007; 29: 423-427.

23 World Health Organization. Global Tuberculosis Control: A Short Update to the 2009 Report. Geneva, World Health Organization, 2009.

24 Corbett EL, Watt CJ, Walker N, et al. The growing burden of tuberculosis: global trends and interactions with the HIV epidemic. Arch Intern Med 2003; 163: 1009-1021.

25 World Health Organization. Interim Policy on Collaborative TB/ HIV Activities. Geneva, World Health Organization, 2004.

26 Friedland G, Harries A, Coetzee D. Implementation issues in tuberculosis/HIV program collaboration and integration: 3 case studies. J Infect Dis 2007; 196: Suppl. 1, S114-S123.

27 Coker R, McKee M, Atun R, et al. Risk factors for pulmonary tuberculosis in Russia: case-control study. BMJ 2006; 332: 85-87.

28 Tocque K, Bellis MA, Beeching NJ, et al. A case-control study of lifestyle risk factors associated with tuberculosis in Liverpool, North-West England. Eur Respir J 2001; 18: 959-964.

29 Lönnroth K, Williams BG, Stadlin S, et al. Alcohol use as a risk factor for tuberculosis - a systematic review. BMC Public Health 2008; 8: 289.

30 World Health Organization. World Health Statistics 2008. Geneva, World Health Organization, 2008.

31 Wild S, Roglic G, Green A, et al. Global prevalence of diabetes: estimates for the year 2000 and projections for 2030. Diabetes Care 2004; 27: 1047-1053.

32 Blas E, Sivasankara AK, eds. Priority Public Health Conditions: From Learning to Action on Social Determinants of Health. Geneva, World Health Organization, 2010.

33 Szabo G. Alcohol and susceptibility to tuberculosis. Alcohol Health Res World 1997; 21: 39-41.

34 WHO Expert Committee on Problems Related to Alcohol Consumption: Second Report. In WHO Technical Report Series 944. Geneva, World Health Organization, 2007.

35 Mellencamp M. Effects of ethanol consumption on susceptibility to pulmonary and gastrointestinal infections. Alcohol Clin Exp Res 1996; 20: 192-195.

36 Szabo G. Alcohol's contribution to compromised immunity. Alcohol Health Res World 1997; 21: 30-41.

37 Houtmeyers E, Gosselink R, Gayan-Ramirez G, et al. Regulation of mucociliary clearance in health and disease. Eur Respir J 1999; 13: $1177-1188$

38 Sopori M. Effects of cigarette smoke on the immune system. Nat Rev Immunol 202, 2: 372-377.

39 Wang H, Yu M, Ochani M, et al. Nicotinic acetylcholine receptor $\alpha 7$ subunit is an essential regulator of inflammation. Nature 2003; 421: 384-388.

40 World Health Organization, International Union Against Tuberculosis and Lung Disease, World Diabetes Foundation. Report from the Expert Meeting on Tuberculosis and Diabetes Mellitus. Geneva, World Health Organization, 2009.
41 Rehm J, Samokhvalov AV, Neuman MG, et al. The association between alcohol use, alcohol use disorders and tuberculosis (TB). A systematic review. BMC Public Health 2009; 9: 450.

42 Salvi SS, Barnes PJ. Chronic obstructive pulmonary disease in non-smokers. Lancet 2009; 374: 733-743.

43 Sweetland A, Acha J, Guerra D. Enhancing adherence: the role of group psychotherapy in the treatment of MDR-TB in urban Peru. In: Cohen A, Kleinman A, Saraceno B, eds. World Mental Health Casebook: Social and Mental Health Programmes in LowIncome Countries. New York, Kluwer Academic Press, 2002; pp. 57-85.

44 Lönnroth K, Raviglione M. Global Epidemiology of Tuberculosis: Prospects for Control. Semin Respir Crit Care Med 2008; 29: 481-491.

45 Chakrabarti B, Calverley P, Davies P. Tuberculosis and its incidence, special nature, and relationship with chronic obstructive pulmonary disease. Int J COPD 2007; 2: 263-272.

46 Barboza CE, Winter DH, Seiscento $\mathrm{M}$, et al. Tuberculosis and silicosis: epidemiology, diagnosis and chemoprophylaxis. J Bras Pneumol 2008; 34: 961-968.

47 Stevenson CR, Critchley JA, Forouhi NG, et al. Diabetes and the risk of tuberculosis: a neglected threat to public health. Chronic Ill 2007; 3: 228-245.

48 Dooley KE, Chaisson RE. Tuberculosis and diabetes mellitus: convergence of two epidemics. Lancet Infect Dis 2009; 9: 737-746.

49 Stevenson CR, Forouhi NG, Roglic G, et al. Diabetes and tuberculosis: the impact of the diabetes epidemic on tuberculosis incidence. BMC Public Health 2007; 7: 234.

50 Guler M, Unsal E, Dursun B, et al. Factors influencing sputum smear and culture conversion time among patients with new case pulmonary tuberculosis. Int J Clin Pract 2007; 61: 231-235.

51 Wada M. [The effectiveness of pyrazinamide-containing sixmonth short course chemotherapy]. Kekkaku 2000; 75: 665-673.

52 Wang CS, Yang CJ, Chen HC, et al. Impact of type 2 diabetes on manifestations and treatment outcome of pulmonary tuberculosis. Epidemiol Infect 2009; 137: 203-210.

53 Dooley KE, Tang T, Golub JE, et al. Impact of diabetes mellitus on treatment outcomes of patients with active tuberculosis. Am J Trop Med Hyg 2009; 80: 634-639.

54 Maalej S, Belhaoui N, Bourguiba M, et al. [Pulmonary tuberculosis and diabetes. A retrospective study of 60 patients in Tunisia]. Presse Med 2009; 38: 20-24.

55 Mboussa J, Monabeka H, Kombo M, et al. [Course of pulmonary tuberculosis in diabetics]. Rev Pneumol Clin 2003; 59: 39-44.

56 Mellencamp M. Symposium: Effects of ethanol consumption on susceptibility to pulmonary and gastrointestinal infections. Alcohol Clin Exp Res 1996; 20: 192-195.

57 Rieder H. Epidemiologic basis of tuberculosis control. Paris International Union Against Tuberculosis and Lung Disease, 1999.

58 Slama K, Chiang CY, Enarson DA, et al. Tobacco and tuberculosis: a qualitative systematic review and meta-analysis. Int J Tuberc Lung Dis 2007; 11: 1049-1106.

59 Houtmeyers E, Gosselink R, Gayan-Ramirez G, et al. Regulation of mucociliary clearance in health and disease. Eur Respir J 1999; 13: $1177-1188$.

60 Inghammar M, Ekbom A, Engström G, et al. COPD and the risk of tuberculosis - a population-based cohort study. PLoS One 2010; 5: e10138.

61 Lam KB, Jiang CQ, Jordan RE, et al. Prior TB, smoking, and airflow obstruction: a cross-sectional analysis of the Guangzhou Biobank Cohort Study. Chest 2010; 137: 593-600.

62 Willcox PA, Ferguson AD. Chronic obstructive airways disease following treated pulmonary tuberculosis. Respir Med 1989; 83: 195-198.

63 Pauwels RA, Buist AS, Calverley PM, et al. Global strategy for the diagnosis, management, and prevention of chronic obstructive 
pulmonary disease: NHLBI/WHO Global Initiative for Chronic Obstructive Lung Disease (GOLD) Workshop summary. Am J Respir Crit Care Med 2001; 163: 1256-1276.

64 Snider GL, Doctor L, Demas TA, et al. Obstructive airway disease in patients with treated pulmonary tuberculosis. Am Rev Respir Dis 1971; 103: 625-640.

65 Leyton GB. Effects of slow starvation. Lancet 1946; 2: 253-255.

66 McKeown T, Brown RG. Medical evidence related to English population changes in the eighteenth century. Population Studies 1955; ix: 119-141.

67 McKeown T, Record RG. Reasons for the decline of mortality in England and Wales during the nineteenth century. Population Studies 1962; xvi: 94-122.

68 Lönnroth K, Williams BG, Cegielski P, et al. A consistent loglinear relationship between tuberculosis incidence and bodymass index. Int J Epidemiology 2010; 39: 149-155.

69 Leung CC, Lam TH, Chan WM, et al. Lower risk of tuberculosis in obesity. Arch Intern Med 2007; 167: 1297-1304.

70 Leimane V, Riekstina V, Holtz TH, et al. Clinical outcome of individualised treatment of multidrug-resistant tuberculosis in Latvia: a retrospective cohort study. Lancet 2005; 365: 318-326.

71 Kim DK, Kim HJ, Kwon SY, et al. Nutritional deficit as a negative prognostic factor in patients with miliary tuberculosis. Eur Respir J 2008; 32: 1031-1036.

72 Khan A, Sterling TR, Reves R, et al. Lack of weight gain and relapse risk in a large tuberculosis treatment trial. Am J Respir Crit Care Med 2006; 174: 344-348.

73 Rees D, Murray J. Silica, silicosis and tuberculosis. Int J Tuberc Lung Dis 2007; 11: 474-484.

74 Hnizdo E, Murray J. Risk of pulmonary tuberculosis relative to silicosis and exposure to silica dust in South African gold miners. Occup Environ Med 1998; 55: 496-502.

75 teWaternaude JM, Ehrlich RI, Churchyard GJ, et al. Tuberculosis and silica exposure in South African gold miners. Occup Environ Med 2006; 63: 187-192.

76 Calvert GM, Rice FL, Boiano JM Sheehy JW, et al. Occupational silica exposure and risk of various diseases: an analysis using death certificates from 27 states of the United States. Occup Environ Med 2003; 60: 122-129.

77 Churchyard GJ, Kleinschmidt I, Corbett EL, et al. Factors associated with an increased case-fatality rate in HIV-infected and non-infected South African gold miners with pulmonary tuberculosis. Int J Tuberc Lung Dis 2000; 4: 705-712.

78 Murray J, Sonnenberg P, Shearer S, et al. Drug resistant pulmonary tuberculosis in a cohort of southern African gold miners with a high prevalence of HIV infection. S Afr Med J 2000; 90: 381-386.

79 Prince M, Patel V, Saxena S, et al. No health without mental health. Lancet 2007; 370: 859-877.

80 Aghanwa HS, Erhabor GE. Demographic/socioeconomic factors in mental disorders associated with tuberculosis in southwest Nigeria. J Psychosom Res 1998; 45: 353-60.

81 Carta MG, Coppo P, Carpiniello B, et al. Mental disorders and health care seeking in Bandiagara: a community survey in the Dogon Plateau. Soc Psychiatry Psychiatr Epidemiol 1997; 32: 222-229.

82 Schuckit MA. Comorbidity between substance use disorders and psychiatric conditions. Addiction 2006; 101: S76-S88.

83 Levinsky L. Tuberculosis and cardiopulmonary failure. Dis Chest 1961; 40: 564-571.

84 Ehlers S. Tumor necrosis factor and its blockade in granulomatous infections: differential modes of action of infliximab and etanercept? Clin Infect Dis 2005; 41: Suppl. 3, S199-S203.

85 Keane J, Gershon S, Wise RP, et al. Tuberculosis associated with infliximab, a tumor necrosis factor $\alpha$-neutralizing agent. $N$ Engl J Med 2001; 345: 1098-1104.
86 Gomez-Reino JJ, Carmona L, Angel Descalzo M. Risk of tuberculosis in patients treated with tumor necrosis factor antagonists due to incomplete prevention of reactivation of latent infection. Arthritis and rheumatism 2007; 57: 756-761.

$87 \mathrm{Al}$ Shohaib S. Tuberculosis in chronic renal failure in Jeddah. J Infect 2000; 40: 150-153.

88 Abdelrahman M, Sinha AK, Karkar A. Tuberculosis in end-stage renal disease patients on hemodialysis. Hemodial Int 2006; 10: 360-364.

89 World Health Organization. Global Tuberculosis Control: Surveillance, Planning, Financing. Geneva, World Health Organization, 2007.

90 Raviglione MC, Uplekar MW. WHO's new Stop TB Strategy. Lancet 2006; 367: 952-955.

91 Me'emary F, Ottmani SE, Pio A, et al. Results of the feasibility test of the Practical Approach to Lung Health in the Syrian Arab Republic. East Mediterr Health J 2009; 15: 504-515.

92 Camacho M, Nogales M, Manjon R, et al. Results of PAL feasibility test in primary health care facilities in four regions of Bolivia. Int J Tuberc Lung Dis 2007; 11: 1246-1252.

93 Brimkulov N, Ottmani SE, Pio A, et al. Feasibility test results of the Practical Approach to Lung Health in Bishkek, Kyrgyzstan. Int J Tuberc Lung Dis 2009; 13: 533-539.

94 World Health Organization. Practical Approach to Lung Health - Manual on initiating PAL implementation. Geneva, World Health Organization, 2008.

95 Halbert RJ, Isonaka S, George D, et al. Interpreting COPD prevalence estimates: what is the true burden of disease? Chest 2003; 123: 1684-1692.

96 Shafey O, Dolwick S, Guindon GE, eds. Tobacco Control Country Profiles 2003. 2nd Edn. Atlanta, American Cancer Society, 2003.

97 World Health Organization. WHO Global Status Report on Alcohol 2004. Geneva, World Health Organization, 2004.

98 Alberg AJ. Cigarette smoking: health effects and control strategies. Drugs Today 2008; 44: 895-904.

99 Kimerling ME, Shakes CF, Carlisle R, et al. Spot sputum screening: evaluation of an intervention in two homeless shelters. Int J Tuberc Lung Dis 1999; 3: 613-619.

100 Barry MA, Wall C, Shirley L, et al. Tuberculosis screening in Boston's homeless shelters. Public Health Rep 1986; 101: 487-494.

101 Goldgrub N, Santos LAR, Galesi VMN. Active case finding campaign in homeless shelters in Sao Paulo City, Brazil. Int J Tuberc Lung Dis 2002; 6: Suppl. 1, S153.

102 Galesi VMN, Almeida MMMB, Santos LAR. Tuberculosis casefinding campaign, Sao Paulo, Brazil. Int J Tuberc Lung Dis 2001; 5: S91-S92.

103 Diez M, Bleda MJ, Alcaide J. Determinants of health system delay among confirmed tuberculosis cases in Spain. Eur J Public Health 2005; 15: 343-349.

104 Snider DE. The relationship between tuberculosis and silicosis. Am Rev Respir Dis 1978; 118: 455-460.

105 Dye C, Floyd K. Tuberculosis. In: Jamison DT, Breman JG, Measham AR, et al. eds. Disease Control Priorities in Developing Countries. 2nd Edn. New York, Oxford University Press, 2006. pp. 289-309.

106 Laxminarayan R, Klein E, Dye C, et al. Economic Benefit of Tuberculosis Control. World Bank Policy Research Working Paper No. 4295. New York, World Bank, 2007.

107 Baily GVJ, Savic D, Gothi G D, et al. Potential yield of pulmonary tuberculosis cases by direct microscopy of sputum in a district of South India. Bull World Health Org 1967; 37: 875-892.

108 Golub JE, Mohan CI, Comstock GW, et al. Active case finding of tuberculosis: historical perspective and future prospects. Int $J$ Tuberc Lung Dis 2005; 9: 1183-1203. 
109 Tuberculosis Coalition for Technical Assistance. International Standards for Tuberculosis Care (ISTC), 2nd Edn. The Hague, Tuberculosis Coalition for Technical Assistance, 2009.

110 Franke MF, Appleton SC, Bayona J, et al. Risk factors and mortality associated with default from multidrug-resistant tuberculosis treatment. Clin Infect Dis 2008; 46: 1844-1845.

111 Gelmanova IY, Keshavjee S, Golubchikova VT, et al. Barriers to successful tuberculosis treatment in Tomsk, Russian Federation: non-adherence, default and the acquisition of multidrug resistance. Bull World Health Organ 2007; 85: 703-711.

112 Koriakin VA, Sokolova GB, Grinchar NA, et al. [Pharmacokinetics of isoniazid in patients with pulmonary tuberculosis and alcoholism.] Probl Tuberk 1986; 12: 43-46.

113 Nijland HM, Ruslami R, Stalenhoef JE, et al. Exposure to rifampicin is strongly reduced in patients with tuberculosis and type 2 diabetes. Clin Infect Dis 2006; 43: 848-854.

114 Thompson NP, Caplin ME, Hamilton MI, et al. Antituberculosis medication and the liver: dangers and recommendations in management. Eur Respir J 1995; 8: 1384-1388.

115 Pande JN, Singh SP, Khilnani GC, et al. Risk factors for hepatotoxicity from antituberculosis drugs: a case-control study. Thorax 1996; 51: 132-136.

116 Janssens B, Van Damme W, Raleigh B, et al. Offering integrated care for HIV/AIDS, diabetes and hypertension within chronic disease clinics in Cambodia. Bull World Health Organ 2007; 85: 880-885.

117 Laserson KF, Wells CD. Reaching the targets for tuberculosis control: the impact of HIV. Bull World Health Organ 2007; 85: 377-381.

118 Maher D, Harries AD, Zachariah R, et al. A global framework for action to improve the primary care response to chronic noncommunicable diseases: a solution to a neglected problem. BMC Public Health 2009; 9: 355.

119 40th Union World Conference on Lung Health, Cancun, Mexico, 2009.

120 Brostrom R. Integrating Diabetes and TB Programs. www. nationaltbcenter.ucsf.edu/training/webarchive/tbdm/docs / CNTC_TBDM_Dec1009_Richard_Brostrom_Handout.pdf Date last accessed: February 9, 2011. Date last updated: December 10, 2009.

121 Wilk AI, Jensen NM, Havighurst TC. Meta-analysis of randomized control trials addressing brief interventions in heavy alcohol drinkers. J Gen Intern Med 1997; 12: 274-283.

122 Poikolainen K. Effectiveness of brief interventions to reduce alcohol intake in primary health care populations: a metaanalysis. Prev Med 1999; 28: 503-509.

123 Room R, Babor T, Rehm J. Alcohol and public health: a review. Lancet 2005; 365: 519-530.

124 Berglund M, Thelander S, Jonsson E. Treating alcohol and drug abuse. An evidenced based review. Weinheim, Wiley, 2003.

125 Nolen-Hoeksema S. Gender differences in risk factors and consequences for alcohol use and problems. Clin Psychol Rev 2004; 24: 981-1010.

126 Batty GD, Lewars H, Emslie C. Internationally recognized guidelines for "sensible" alcohol consumption: is exceeding them actually detrimental to health and social circumstances? Evidence from a population-based cohort study. J Public Health 2009; 31: 360-336.

127 International Union Against Tuberculosis and Lung Disease, World Health Organization. A WHO/The Union monograph on TB and tobacco control - joining efforts to control two related global epidemics. Geneva, World Health Organization, 2007.
128 Solberg LI, Maciosek MV, Edwards NM, et al. Repeated tobaccouse screening and intervention in clinical practice. Health impact and cost effectiveness. Am J Prev Med 2006; 31: 62-71.

129 Lancaster T, Stead L. Physician advice for smoking cessation. Cochrane Database Syst Rev 2004; 4: CD000165.

130 El Sony A, Slama K, Salieh M, et al. Feasibility of brief tobacco cessation advice for tuberculosis patients: a study from Sudan. Int J Tuberc Lung Dis 2007; 11: 150-155.

131 Abba K, Sudarsanam TD, Grobler L, et al. Nutritional supplements for people being treated for active tuberculosis. Cochrane Database Syst Rev 2008; 4: CD006086.

132 Jamieson C, Norton B, Day T, et al. The quantitative effect of nutrition support on quality of life in outpatients. Clinical Nutrition 1997; 16: 25-28.

133 Lettow MV, Kumwenda JJ, Harries AD, et al. Malnutrition and the severity of lung disease in adults with pulmonary tuberculosis in Malawi. Int J Tuberc Lung Dis 2004; 8: 211-217.

134 Papathakis P, Piwoz E. Nutrition and Tuberculosis: A Review of the Literature and Considerations for TB Control Programs. Washington, USAID, 2008.

135 Xie QM, Tang HF, Chen JQ, et al. Pharmacological actions of tetrandrine in inflammatory pulmonary diseases. Acta Pharmacol Sin 2002; 23: 1107-1113.

136 World Health Organization. The Stop TB Strategy: building on and enhancing DOTS to meet the TB-related Millennium Development Goals. Geneva, World Health Organization, 2006.

137 Rehm J, Greenfield TK. Public alcohol policy: current directions and new opportunities. Clin Pharmacol Ther 2008; 83: 640-643.

138 Babor T, Caetano R, Casswell S, et al. Alcohol: No Ordinary Commodity. Research and Public Policy. Oxford, Oxford University Press, 2003.

139 van den Berg $\mathrm{M}$, van Baal $\mathrm{PH}$, Tariq $\mathrm{L}$, et al. The costeffectiveness of increasing alcohol taxes: a modeling study. BMC Med 2008; 6: 36.

140 Shilova MV, Dye C. The resurgence of tuberculosis in Russia. Philos Trans R Soc Lond B Biol Sci 2001; 356: 1069-1075.

141 Arinaminpathy N, Dye C. Health in financial crises: economic recession and tuberculosis in Central and Eastern Europe. J R Soc Interface 2010; 7: 1559-1569.

142 Oeltmann JE, Kammerer JS, Pevzner ES, et al. Tuberculosis and substance abuse in the United States, 1997-2006. Arch Intern Med 2009; 169: 189-197.

143 World Health Organization. WHO Guidelines for the Programmatic Management of Drug-Resistant Tuberculosis. Geneva, World Health Organization, 2008.

144 Francis J. Curry National Tuberculosis Center and California Department of Public Health. Drug-Resistant Tuberculosis: A Survival Guide for Clinicians. 2nd Edn. San Francisco, Francis J. Curry National Tuberculosis Center, 2008.

145 World Health Organization. Global Tuberculosis Control 2009. Geneva, World Health Organization, 2009.

146 Elzinga G, Raviglione MC, Maher D. Scale up: meeting targets in global tuberculosis control. Lancet 2004; 363: 814-819.

147 Dye C, Watt CJ, Bleed DM, et al. What is the limit to case detection under the DOTS strategy for tuberculosis control? Tuberculosis 2003; 83: 35-43.

148 Corbett EL, Bandason T, Duong T, et al. Comparison of two active case-finding strategies for community-based diagnosis of symptomatic smear-positive tuberculosis and control of infectious tuberculosis in Harare, Zimbabwe (DETECTB): a clusterrandomised trial. Lancet 2010; 376: 1244-1253. 